\title{
Five years retrospective cohort analysis of treatment outcomes of TB-HIV patients at a PEPFAR/DOTS Centre in South Eastern Nigeria.
}

\author{
Omotowo I Babatunde ${ }^{1}$, Ekwueme O Christiandolus ${ }^{1}$, Eke C Bismarck², Obi I Emmanuel ${ }^{1}$, \\ Agunwa C Chike ${ }^{1}$ Eyisi I Gabriel ${ }^{1}$
}

1. Department of Community Medicine, College of Medicine, University of Nigeria,
Enugu Campus/University of Nigeria Teaching Hospital, Enugu.
2. Department of Paediatrics, University of Nigeria Teaching Hospital, Enugu, Nigeria

\begin{abstract}
Background: Human immunodeficiency virus (HIV) associated tuberculosis (TB) remains a major global public health challenge, with an estimated 1.4 million patients worldwide. Co-infection with HIV leads to challenges in the diagnosis and treatment of patients.

Objectives: The aim of this study was to assess treatment outcomes of a cohort of smear positive TB-HIV co-infected patients over a five-year study period.

Methods: A retrospective cohort study of 600 smear-positive tuberculosis patients registered at the chest unit of the University of Nigeria Teaching Hospital, Enugu from January 2008 to December 2012 was done. The data was analyzed using SPSS Version 17.

Results: One hundred and three (17.2\%) of the patients were co-infected with TB/HIV, while $398(66.3 \%)$ and $99(16.5 \%)$ were HIV negative and unknown respectively. Among the co-infected patients, 45(43.7\%) were cured as against 222(55.8\%) in the TBHIV negatives $(Z=4.53, \mathrm{p}=0.000,95 \% \mathrm{CI}=0.12-0.34)$. Respectively in the TB-HIV co-infected and TB-HIV negative patients, treatment completed were $21(20.4 \%)$ and $71(17.8 \%)(Z=9.15, \mathrm{p}=0.000,95 \%=0.4035-0.60)$; defaulted $19(18.5 \%)$ vs $70(17.6 \%)$ $(\mathrm{Z}=9.29, \mathrm{p}=0.000,95 \% \mathrm{CI}=0.42-0.60)$, died $10(9.7 \%)$ vs. $6(1.5 \%)(\mathrm{Z}=1.22, \mathrm{p}=0.224,95 \% \mathrm{CI}=-0.0286-0.1086)$, and failures were $1(0.9 \%)$ vs. $7(1.8 \%)(\mathrm{Z}=2.48, \mathrm{p}=0.013,95 \% \mathrm{CI}=0.04-0.10)$. Treatment success rate was lower in TB-HIV co-infected patients, $64.1 \%$ compared to TB-HIV negative patients with 73.6\%. Also those that defaulted among the TB-HIV co-infected patients $(18.5 \%)$ were higher than $17.6 \%$ among TB-HIV negative patients, a difference of $0.9 \%$.

Conclusion: Findings demonstrate that HIV co-infection affects TB treatment outcomes adversely. Treatment adherence, timely and sustained access to antiretroviral therapy for TB/HIV co-infected patients are important.

Keywords: Retrospective cohort analysis, PEPFAR/DOTS centre, South Eastern Nigeria.

DOI: http://dx.doi.org/10.4314/ahs.v16i3.3

Cite as: Babatunde OI, Christiandolus EO, Bismarck EC, Emmanuel OI, Chike AC, Gabriel EI. Five years retrospective cohort analysis of treatment outcomes of TB-HIV patients at a PEPFAR/DOTS Centre in South Eastern Nigeria. Afri Health Sci 2016;16(3): 655-662. DOI: http://dx.doi.org/10.4314/abs.v16i3.3
\end{abstract}

\section{Introduction}

Tuberculosis (TB) now ranks alongside as a leading cause of death worldwide, while TB and Human Immunodeficiency Virus (HIV) are among the 10 leading causes of death in Africa ${ }^{1,2}$. HIV fuels the TB epidemic, while TB is

\footnotetext{
Corresponding author:

Omotowo I Babatunde,

Department of Community Medicine, College of

Medicine, University of Nigeria, Enugu Campus/Uni-

versity of Nigeria Teaching Hospital, Enugu.

Enugu, Nigeria,

Phone: +2348065819918

E mail:babatundeomotowo@yahoo.com
}

the commonest cause of death among people living with $\mathrm{HIV}^{1}$. Out of 1.2 million estimated deaths due to HIV, TB accounted for 0.4 million deaths among HIV positive people ${ }^{1}$.Globally, 9.6 million people are estimated to have fallen ill with TB in 2014. Men constituted the highest 5.4 million, women 3.2 million, while children were 1.0 million. $12 \%$ of the new cases in 2014 were HIV positive. Also, WHO estimated 1.2 million people living with HIV developed TB in 2014. However, only 6 million new TB cases were reported in $2014^{1}$.

Recently, Nigeria was ranked thirteenth among the 22 high burden countries in the world that accounted for 80 percent of TB cases, with a total of $564,460 \mathrm{~TB}$ cases

African Health Sciences Vol 16 Issue 3, September 2016 
occurring annually. The overall TB prevalence in Nigeria reported in 2014 was 330 per 100,000 population, and HIV prevalence during the period was $18 \%$ among incident TB cases ${ }^{1}$. HIV prevalence increased from $2.2 \%$ in 1991 to about $27 \%$ in 2008 . $^{3,4,5}$. In 2014 , total TB cases notified were 91,354 , while $\mathrm{HIV}$-positive TB patients was about $19 \%{ }^{1}$.

Tuberculosis is also a leading killer disease among people living with Human immunodeficiency virus (PLHIV), with an estimated one in four deaths among PLHIV attributable to TB. ${ }^{6}$ The Human immunodeficiency virus (HIV) is one of the most important risk factors associated with an increased risk of latent TB infection progressing to active TB disease. ${ }^{7}$ The World Health Organization (WHO) reported that the proportion of TB cases co-infected with HIV was highest in countries in African region in 2014. Overall, $32 \%$ of TB cases were estimated to be co-infected, which accounted for $74 \%$ of TB cases among people living HIV worldwide ${ }^{1}$.

The Human immunodeficiency virus (HIV) pandemic presents a significant challenge to global tuberculosis (TB) control. ${ }^{7} \mathrm{HIV}$-infected people have an annual risk of $5 \%$ to $15 \%$ of developing active TB once infected. ${ }^{8}$ In a presentation at the Physician Research network, Munsiff reported that more than half of TB cases in many subSaharan African countries are in HIV-infected persons, and that AIDS epidemic has caused marked acceleration of the TB epidemic worldwide particularly in Africa ${ }^{8}$.

The HIV/AIDS pandemic is not only fuelling the burden of TB, but also poses a great challenge to its diagnosis and management ${ }^{1}$. It is also one of the factors responsible for the non-achievement of the WHO TB detection and cure rate targets of $70 \%$ and $85 \%$ respectively 9 . As TB and HIV are known to potentially enhance and worsen the effects of each other, to successfully mitigate the dual burden of TB/HIV in populations at risk of, or affected by both diseases, the World Health Organization (WHO) recommends a combination of measures which includes priority on operational research and collaborative activities involving intensified case finding, preventive and curative therapy. ${ }^{6,7}$ The necessity of sustaining the collaborative efforts among the stakeholders in the common fight against TB and HIV was emphasized in the 2014 World TB and HIV/AIDs days, where all the partners caring for those most at risk of the dual diseases were called upon to continue to work together to ensure the elimination of TB as a public health problem by 2050, and achieving the bold target of ending AIDS together by $2030 .^{10,11}$

The devastating effects of TB and HIV/AIDS to health and human development, and its immediate and grave public health and socio-economic threat in developing countries have made it to be declared a global emergency $^{12}$. By March, 2013, 84 countries had reported at least one MDR-TB case, with grave consequences to the Nations' TB-HIV treatment and control programs. Our study was to find out the treatment outcomes of TB-HIV positive and TB-HIV negative patients treated within the period.

\section{Methods}

\section{Study design}

This is a cross sectional study, five years retrospective cohort analysis of the treatment outcomes of smear positive TB and TB/HIV co-infected cases seen and treated at the Presidential Emergency Programme Fund for Aids Relief (PEPFAR) and Directly Observed Treatment Short course (DOTS) units at the University of Nigeria Teaching Hospital ( UNTH), Enugu, Nigeria. In each centre, patients are offered the opportunity to be screened for both TB and HIV, and referred appropriately depending on the results for further confirmatory investigation and management.

\section{Patients and data collection}

We retrieved folders and treatment cards for TB patients registered in the TB central register between the 1 st of January 2008 and 31st December, 2012 from the institution's records department. The folders were sorted and marked positive or negative according to sputum smear results. The folders marked sputum smear positives were further classified using the laboratory results as TB-HIV positive cases (TB/HIV co-infected), TB-HIV negative cases, and unknown HIV status. A total of 950 case files were reviewed, 250 were sputum smear negatives, while 700 were sputum smear positives. Out of the $700 \mathrm{spu}-$ tum smear positives, 100 did not meet the stated eligibility or inclusion criteria. Thus, all together, 600 case files were included for the study (Figure 1). 


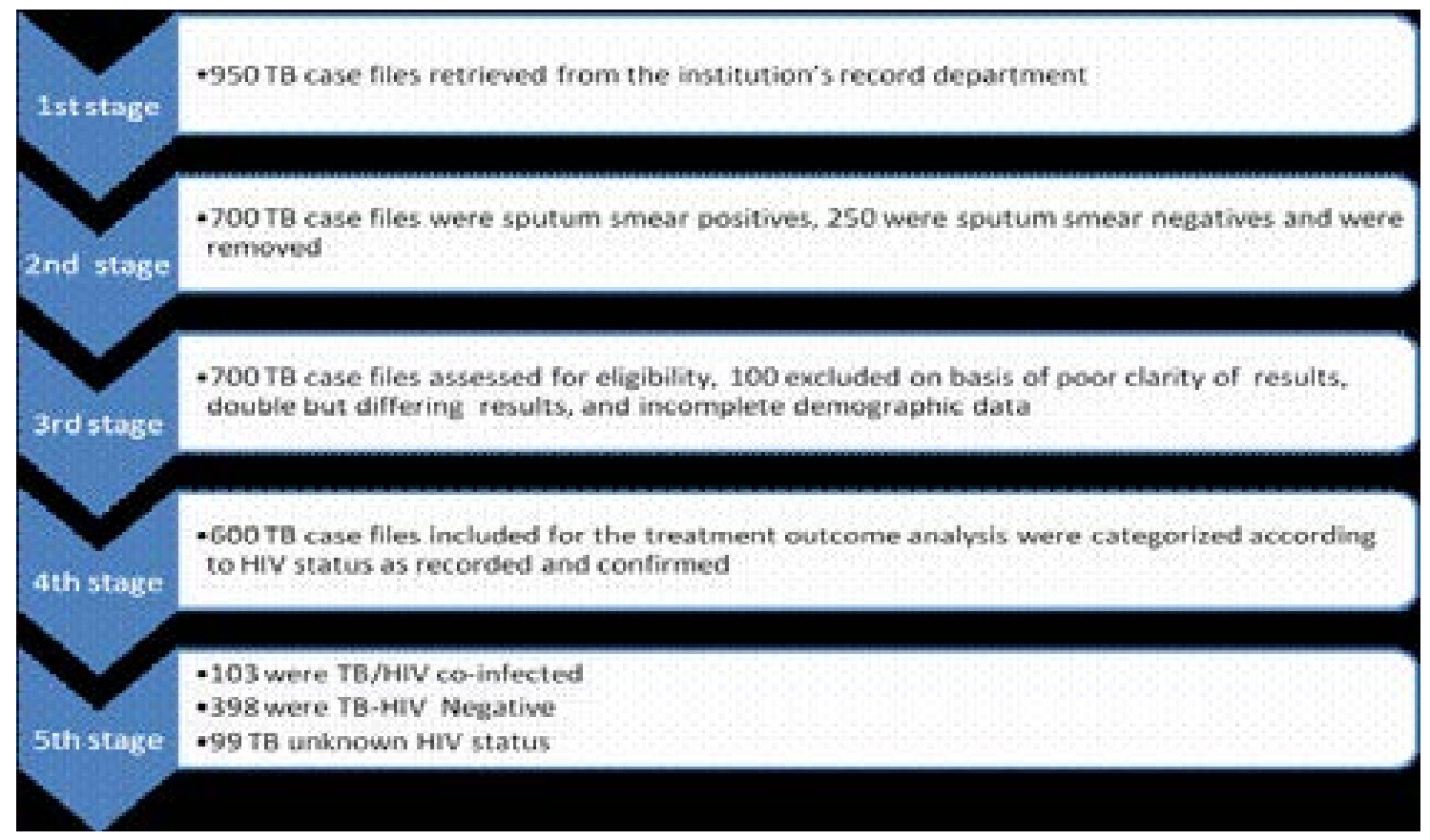

\section{Treatment outcome definitions}

Treatment outcomes were defined according to Nigeria National Tuberculosis and Leprosy Control Programme Guidelines $^{3}$. Cured defined as any patient who was smear positive at diagnosis, who completed treatment and who is smear negative at the end of 6th or 7 th month of treatment and at least one previous occasion. Treatment completed regarded as any patient who was smear positive at diagnosis and who completed treatment but in whom smear examination results are not available at the end of treatment. Treatment failure is any patient who remains or becomes smear positive again at the end of $5^{\text {th }}$ month or later during chemotherapy. TB death defined as any patient who died during the course of his/her chemotherapy irrespective of the cause of death. Defaulter is any patient who has interrupted treatment for 8 consecutive weeks or more after the date of the last attendance during the course of his or her treatment. Transferred out case is a patient who has been transferred to another treatment centre in another state and whose treatment result is not known. Treatment Success is the sum total of patients that were cured and those that completed treatment ${ }^{3}$.

\section{Data analyses}

The data was analyzed and frequencies calculated us- ing Statistical Package for Social Sciences software programme (SPSS) version 17. Chi-square was used to test for associations between categorical variables, and $\mathrm{p}$ values $<0.05$ were considered significant. We used Statistics Data Analysis (STATA) version 13.1 to calculate relative risks of TB treatment outcomes/Deaths and HIV status, and also calculate the risk ratio of death while on TB treatment caused by HIV.

\section{Ethical approval}

Ethical approval for this study was obtained from the Ethical Review Committee of University of Nigeria Teaching Hospital, Enugu, Nigeria. Approval and permission was also obtained from the administrative officers in charge of the chest and PEPFAR ART clinics, and record department of UNTH, Enugu.

\section{Results}

Table 1 shows demographic characteristics of 600 sputum smear positive TB patients that were registered between $1^{\text {st }}$ January 2008 and $31^{\text {st }}$ December 2012. One Hundred and three $(17.2 \%)$ of the patients were HIV positive, while $398(66.3 \%)$ and 99 (16.5\%) were HIV negative and unknown respectively. The difference between the TBHIV positive and TB-HIV negative is statistically significant $(X 2=201.781, \mathrm{p}=0.000)$. More females $(53.4 \%)$ were 
registered among the dually infected patients than among (40.8\%) and TB-HIV negatives (45\%) were within the TB-HIV negative $(X 2=7.158, p=0.028,95 \% \mathrm{CI}=0.3111-\quad$ age groups of $21-30$ years $(\mathrm{X} 2=15.042, \mathrm{p}=0.001,95 \%$ 0.52690. Majority of patients in the both dually infected $\mathrm{CI}=0.1369-0.3484)$.

\begin{tabular}{|c|c|c|c|c|c|c|c|c|c|}
\hline \multirow{4}{*}{$\begin{array}{l}\text { Demographic } \\
\text { Characteristics }\end{array}$} & \multirow{3}{*}{\multicolumn{2}{|c|}{$\begin{array}{l}\text { TB-HIV } \\
\text { positive } \\
(n=103),\end{array}$}} & \multirow{2}{*}{\multicolumn{2}{|c|}{$\begin{array}{l}\text { TB-HIV negative } \\
(n=398),\end{array}$}} & \multirow{3}{*}{\multicolumn{2}{|c|}{$\begin{array}{l}\text { TB-unknown HIV } \\
\text { Status } \\
\qquad(n=99)\end{array}$}} & \multirow[t]{4}{*}{$x^{2}$} & \multirow[t]{4}{*}{$p$-value } & \multirow[t]{4}{*}{$95 \% \mathrm{Cl}$} \\
\hline & & & & & & & & & \\
\hline & & & & & & & & & \\
\hline & $\mathrm{N}$ & $(\%)$ & $\mathrm{N}$ & (\%) & $\mathrm{N}$ & $(\%)$ & & & \\
\hline \multicolumn{10}{|l|}{ Sex: } \\
\hline Male & 48 & 46.6 & 267 & 67.1 & 54 & 54.5 & 4.240 & 0.120 & $0.1038-0.3217$ \\
\hline Female & 55 & 53.4 & 131 & 32.9 & 45 & 45.5 & 7.158 & 0.028 & $0.3111-0.5209$ \\
\hline \multicolumn{10}{|c|}{ Age Group (Years): } \\
\hline $10-20$ & 9 & 8.7 & 35 & 8.8 & 20 & 20.2 & 8.554 & 0.014 & $0.1702-0.3268$ \\
\hline $21-30$ & 42 & 40.8 & 179 & 45.0 & 15 & 15.1 & 15.042 & 0.001 & $0.1369-0.3484$ \\
\hline $31-40$ & 27 & 26.2 & 94 & 23.6 & 18 & 18.2 & 1.254 & 0.534 & $0.5677-0.7531$ \\
\hline $41-50$ & 12 & 11.7 & 47 & 11.8 & 23 & 23.2 & 6.552 & 0.038 & $0.2537-0.4232$ \\
\hline $51-60$ & 10 & 9.7 & 21 & 5.3 & 14 & 14.1 & 8.204 & 0.017 & $0.0223-0.1750$ \\
\hline $61-70$ & 3 & 2.9 & 16 & 4.0 & 6 & 6.1 & 1.152 & 0.562 & $0.0610-0.1762$ \\
\hline$>70$ & 0 & 0 & 6 & 1.5 & 3 & 3.1 & 4.234 & 0.120 & $0.0108-0.0893$ \\
\hline \multicolumn{10}{|l|}{ Marital Status: } \\
\hline Married & 39 & 37.9 & 231 & 58.0 & 46 & 46.5 & 4.983 & 0.083 & $0.0555-0.2680$ \\
\hline Single & 58 & 56.3 & 161 & 40.5 & 49 & 49.5 & 3.473 & 0.176 & $0.3098-0.5202$ \\
\hline Widowed & 5 & 4.9 & 2 & 0.5 & 2 & 2.0 & 8.406 & 0.015 & $-0.0074-0.0978$ \\
\hline Divorced & 1 & 0.9 & 1 & 0.2 & 0 & 0 & $1.567^{*}$ & 0.457 & $-0.0197-0.0506$ \\
\hline Not & 0 & 0 & 3 & 0.8 & 2 & 2.0 & 2.919 & 0.232 & $-0.0169-0.0533$ \\
\hline \multicolumn{10}{|l|}{ Documented } \\
\hline \multicolumn{10}{|l|}{ Occupation: } \\
\hline Student & 34 & 33.0 & 105 & 26.4 & 40 & 40.3 & 4.169 & 0.125 & $0.1396-0.3394$ \\
\hline Civil Servant & 23 & 22.3 & 21 & 5.3 & 17 & 17.2 & 25.224 & 0.000 & $-0.0668-0.1227$ \\
\hline Farmer & 12 & 11.7 & 14 & 3.5 & 23 & 23.2 & 33.874 & 0.000 & $-0.0584-0.858$ \\
\hline Driver & 21 & 20.4 & 1 & 0.2 & 6 & 6.1 & 62.289 & 0.000 & $0.1264-0.2939$ \\
\hline House wife & 11 & 10.7 & 3 & 0.8 & 1 & 1.1 & 22.143 & 0.000 & $0.0243-0.1619$ \\
\hline Others & 2 & 1.9 & 254 & 63.8 & 12 & 12.1 & 82.182 & 0.000 & $0.1643-0.2831$ \\
\hline
\end{tabular}

Chi square of the HIV status of the patients: $X 2=201.781 \quad p=0.000$

Among the co-infected patients, 45(43.7\%) were cured as against $222(55.8 \%)$ in the TB-HIV negatives $(\mathrm{Z}=4.53$, $\mathrm{p}=0.000,95 \% \mathrm{CI}=0.1175-0.3385)$. Respectively in the TB-HIV co-infected and TB-HIV negative patients, treatment completed were $21(20.4 \%)$ and $71(17.8 \%)(\mathrm{Z}=9.15$ $\mathrm{p}=0.000, \quad 95 \%=0.4035-0.5965)$; while failures were $1(0.9 \%)$ vs. $7(1.8 \%)(\mathrm{Z}=2.48, \mathrm{p}=0.013,95 \% \mathrm{CI}=0.0371$ $0.1009)$. Treatment success rate was lower in TB-HIV coinfected patients, $64.1 \%$ compared to TB-HIV negative patients with $73.6 \%$. (Table 2 ) 


\section{Table 2: Treatment outcomes of the TB patients in relation to HIV status}

\begin{tabular}{|c|c|c|c|c|c|c|c|c|c|}
\hline Treatment outcomes & \multicolumn{2}{|c|}{$\begin{array}{l}\text { TB-HIV Positive } \\
\text { N = } 103 \text { (\%) }\end{array}$} & $\begin{array}{r}\text { TB-HIV Ne } \\
\mathrm{N}=398\end{array}$ & $\begin{array}{l}\text { gative } \\
(\%)\end{array}$ & $\begin{array}{l}\text { TB- } \\
\text { HIV } \\
\mathrm{N}=\end{array}$ & $\begin{array}{l}\text { known } \\
\text { atus } \\
(\%)\end{array}$ & Z score & P-value & $95 \% \mathrm{Cl}$ \\
\hline Cured & 45 & 43.7 & 222 & 55.8 & 61 & 61.6 & 4.53 & 0.000 & $0.1175-0.3385$ \\
\hline Completed & 21 & 20.4 & 71 & 17.8 & 9 & 9.1 & 9.15 & 0.000 & $0.4035-0.5965$ \\
\hline Defaulted & 19 & 18.5 & 70 & 17.6 & 20 & 20.2 & 9.29 & 0.000 & $0.415-0.6042$ \\
\hline Transferred out & 7 & 6.8 & 22 & 5.5 & 6 & 6.1 & 3.32 & 0.001 & $0.0800-0.2200$ \\
\hline Died & 10 & 9.7 & 6 & 1.5 & 3 & 3.0 & 1.22 & 0.224 & $0.0286-0.1086$ \\
\hline =ailure & 1 & 0.9 & 7 & 1.8 & 0 & 0.0 & 2.48 & 0.013 & $0.0371-0.1009$ \\
\hline
\end{tabular}

The relative risk of TB treatment unfavourable outcomes and HIV was found to be $\mathrm{RR}=2.09$ at Confidence Interval (CI 1.26 - 3.43); X2 $=7.128, \mathrm{P}=0.028$, and this is statistically significant. The Relative risk of TB treatment unfavourable outcome was higher in the age group (31-40 years) compare to other age groups $\mathrm{RR}=1.47,(\mathrm{CI}=0.88$ $-2.44) ; \mathrm{X} 2=0.756, \mathrm{P}=0.993$. The risk ratio of death while on TB treatment by HIV status was 4.27 at $\mathrm{CI}=$ $1.64-11.06) ; \mathrm{X} 2=10.61, \mathrm{P}=0.001$.

\section{Discussion}

HIV infection is considered the main risk factor for the increase in the number of TB patients and poor treatment outcomes. Regional and countries studies on TB/ HIV co-infection revealed a wide prevalence values ranging between $2.93 \%$ to $72.34 \%$, with pooled prevalence value of $23.51 \%$ (95\% CI 20.91-26.11)14. Other survey studies focusing on treatment outcome of TB/HIV coinfection in positive and negative smear pulmonary tuberculosis patients within Nigeria, sub-Sahara Africa and Asian countries also found high and differing co-infection rates ranging from $23 \%$ to $42 \% .^{5,14,19-24}$

In our study, although the sero-prevalence of $17.2 \%$ fall within the wide range as found in the regional and countries studies, it however contrasts the prevalence values range documented in the African sub-regions and Asian countries studies. This finding is not so uncommon because difference co-infection prevalence values have been found within these same country regions, states and communities. Also the difference may be accounted for by the high number of TB patients with unknown or undocumented HIV status in this study (Table 1). However, the prevalence of TB/HIV co-infection in our study is similar to the studies conducted among women attending antenatal care (ANC) in Southern Ethiopia, a four -year retrospective study of HIV in Tuberculosis Patients at University Teaching Hospitals in Nigeria and Indian. ${ }^{25-27}$ The prevalence value found in our study is still within the fluctuating Nigeria National figures of $2.2 \%$ in 1991, $27 \%$ in 2008 and $23 \%$ in 2012 . $^{2,9,12}$ The difference between our study and National figures may be due to the fact that the National HIV prevalence in TB patients includes those with sputum smear negative TB, which is common among positive HIV persons.

The socio-demographic variables of the TB/HIV patients in our study are similar to those of other researchers within and outside Nigerian state ${ }^{26,28,29}$. Although, majority of the TB patients were males, most of the TB/HIV co-infected were females. The high prevalence of HIV co-infection among females could be due to socio-economic and socio-cultural factors affecting women mostly in African countries such as poor quality of life, poor housing, overcrowding, under-nutrition, lack of education and empowerment, social placement of women as inferior to men and harmful traditional practices including violence against women. The most socio-economic productive age group, 21-50 years were most singly and dually affected by TB and TB/HIV. This finding is also similar to studies carried out in Dabat, Ethiopia, Malawi, Cameroonian district hospital and Rwanda. 19,20,28,30. $^{2}$

African Health Sciences Vol 16 Issue 3, September 2016 
These findings compare favourably with the results of the similar survey studies on TB/HIV done in different tertiary institutions in Nigeria ${ }^{15-17}$; and in Ethiopia ${ }^{18}$ where worst treatment outcomes were found among the co-infected than those with TB disease only. Although several other factors may be contributory to the recorded unfavourable treatment outcomes among the TB/HIV infected patients, but the dual immune depressing diseases have been found to be the major culprits. The challenges of dual TB/HIV co-infection was also reported in a study in Indonesia by Pontororing et al where HIV coinfection in TB patients led to challenges in the diagnosis and treatment of patients and so affected the treatment outcomes $^{32}$. The HIV co-infected TB patients that died in our study is more than those reported in the studies done in Cameroon and Malawi, 3.3\% and 5\% respectively. ${ }^{24,25}$ This figure in our study is however less than the studies done in India (19\%) and in a tertiary health facility in southeast Nigeria $(17 \%)^{31}$. The cure rate among the sputum smear positive TB patients who are HIV negative in our study is lower than the WHO recommendation. Also, successful treatment outcome (cured \& completed treatment) was lower in our study than WHO recommendation and Nigeria National TB control target of $85 \%{ }^{2}$. The treatment success rates reported in the studies done in Nylon district hospital, Cameroon and in a district of south India are similar to our findings ${ }^{19,31}$; while HIV/ TB co-infection treatment success rate was higher in the study conducted in Malawi where a success rate of $86 \%$ was found.20 This finding could be due to lack of proper health education on adherence, a situation capable of resulting in Multi Drug resistance TB (MDR-TB).

The defaulter rates for both HIV co-infected TB patients and HIV negative TB patients in our study is above the Nigeria national TB control programme target of less than $10 \%$. The defaulter rate found in our study is higher than $6 \%$ reported in the study done Malawi and 16\% found in India among sputum smear positive TB patients; 20,31 but lower than the failure rate in a survey study done in Cameroon $(23.6 \%)^{19}$. This could be as a result of poor defaulter management despite provision of recharge cards by German Leprosy and TB Relief Association for DOTS providers to make phone calls to defaulters, and also lack of proper health education to patients on completion of their treatment irrespective of any im- provement in their health condition while on TB treatment. The failure rate observed in our study was higher among TB-HIV negative patients than those co-infected. Though this finding ordinarily would be unexpected, but it may not be unrelated to poor adherence as evidenced in the lower treatment completion and higher default rates among the patients. Poor adherence to treatment may be secondary to inconsistency in health education and associated socio-economic factors. However, failure rate reported in our study is similar to findings survey studies done in Malawi (1\%), and South Eastern part of Nigeria $(1.1 \%)^{5,20}$. The result in our study is however less than failure rate of $2 \%$ reported in the study done in India ${ }^{31}$. The high failure rate in our study might be due to emergence of multidrug resistance $\mathrm{TB}$, and probably due to non adherence to the anti TB drugs by those TB patients that are HIV negative compared with TB patients that are HIV sero-positive who may have received health care in the course of management of the dual disease entity.

\section{Conclusion}

This study showed that the proportion of patients coinfected with TB/HIV disease differed significantly from the patients infected with only TB disease. The findings of this study also demonstrated statistically significant differences between the treatment outcome rates among TB/HIV co-infected patients and TB-HIV negatives patients. Urgent health education intervention on adherence factors for all patients registered for treatment and the healthcare providers is needed.

\section{Acknowledgements}

We acknowledge Medical Education Partnership in Nigeria (MEPIN), Fogarty International Center, and Northwestern University .We express gratitude to German Leprosy and TB Relief Association(GLRA), and staff of Enugu State TBL control, PEPFAR/DOTS Centers.

\section{Conflict of interest}

None declare.

\section{References}

1. WHO 2015. Global tuberculosis report 2015. WHO/ HTM/TB/2015.22 http://www.who.int/tb/publications/global_report/en

2. Federal Ministry of Health, Nigeria. National Tubercu- 
losis, Leprosy and Buruli Ulcer Management and Control Guildelines, 6th edition 2015;18-23.

3. Federal Ministry of Health, Nigeria. Guidelines for the control of multi-drug resistant tuberculosis in Nigeria. Department of Public Health. 2008;5-9

4. Stylblo K. The global aspects of tuberculosis and HIV infection. Bull Int Union Tuberc Lung Dis. 1990; 65:28-32. [PubMed]

5. Nwokeukwu HI, Inya-Agha DU, Nwogu KC. Treatment outcome of Tuberculosis and HIV Co-infection at a Tertiary Health in South-Eastern Nigeria. Journal of Community Medicine and Primary Health Care 2013; 25(1): 58-64.

6. World Health Organization /HIV Working Group. Priority research questions for TB: HIV in HIV-prevalent and resource-limited settings. Geneva: WHO Press, 2010 7. WHO. WHO policy on collaborative TB/HIV activities: guidelines for national programmes and other stakeholders. Geneva: WHO Press, 2012

8. King L and Ahuja S. TB and HIV Coinfection: Current Trends, Diagnosis and Treatment Update. In MPH based on a presentation at Physician Research Network, Sonal S. Munsiff, MD 2006.http://www.prn.org/index.php/ coinfections/article/tb_hiv_coinfection_treatment_80

9. WHO 2013. www.who.int/hiv/topics/tb/tbhiv_ facts_2013/en.

10. Center for Disease Control and Prevention. World TB Day 2014. http://www.cdc.gov/tb/events/WorldTBDay/default.htm TB. Treat TB. The 2014 theme for World AIDS Day is "Focus, Partner, Achieve: An AIDS-free Generation. http://aids.gov/

12. WHO 2013. Global tuberculosis report 2013. WHO/ HTM/TB/2013.16 http://www.who.int/tb/publications/global_report/en

13. WHO. Tuberculosis (MDR-TB) Update 2013 http:// www.who.int/tb/challenges/mdr/MDR_TB_FactSheet. pdf

14. Gao J, Zheng P, Fu H . Prevalence of TB/HIV CoInfection in Countries Except China: A Systematic Review and Meta-Analysis. PLoS ONE, 2013, 8(5): PubMed e64915. doi:10.1371/journal.pone.0064915

15. Daniel, O.J., \& Alausa, O.K. Treatment outcome of TB/HIV positive and TB/HIV negative patients on directly observed treatment, short course (DOTS) in
11. U.S department of Health and Human Services . news-and-events/awareness-days/world-aids-day/

Sagamu, Nigeria.http://www.researchgate.net/publication/6685579_Treatment_outcome_of_TBHIV_positive_and_TBHIV_negative_patients_on_directly_observed_treatment_short_course_\%28DOTS\%29_in_ Sagamu_Nigeria

16. Oshi, D.C., Oshi, S.N., Alobu, I. \& Ukwaja K.N. Profile, Outcomes, and Determinants of Unsuccessful Tuberculosis Treatment Outcomes among HIV-Infected Tuberculosis Patients in a Nigerian State. Tuberculosis research and treatment $01 / 2014 ; 2014: 202983$. DOI: $10.1155 / 2014 / 202983$

17. Ifebunandu, N.A., Ukwaja, K.N., \& Obi, S.N. Treatment outcome of HIV-associated tuberculosis in a resource-poor setting. Tropical Doctor (Impact Factor:0.61), 2012; 42(2):74-6. DOI: 10.1258/td.2011.110421

18. Shaweno, D. \& Worku, A. Tuberculosis treatment survival of HIV positive TB patients on directly observed treatment short course in Southern Ethiopia: A retrospective cohort study. BMC Research Notes 12/2012; 5(1):682.

19. Sume GE, Hoshen M, Bita G, Kabore S, Nzima VN. Treatment outcome of TB/HIV positive and negative smear positive pulmonary tuberculosis patients treated using daily self-administered therapy in a Cameroonian district hospital. East Afr Med J 2009;86(10):469 PubMed $-75$

20. Tweya H, Feldacker C, Phiri S et al. Comparison of treatment outcomes of new smear positive pulmonary tuberculosis patients by HIV and antiretroviral status in a TB/HIV clinic, Malawi. PLoS 2013; 8(2): PubMed doi:10.1371/journal.pone.0056248

21. Converse PJ. Dual Infection: The challenge of HIV/ AIDS and Tuberculosis in Ethiopia. Northeast African Studies 2000; 7(1):277-282

22. Demissie M, Lindtjorn B, Tegbaru B: Human Immunodeficiency Virus (HIV) infection in tuberculosis patients in Addis Ababa. Ethiop J Health Dev 2000, 14(3):277 PubMed -282.

23. Dauda M. Evaluation of the efficacy of directly observed treatment short course (DOTS) in patients with tuberculosis and HIV Co-infection in Kano, Nigeria. RIF 2010; 1(5):218 PubMed -223.

24. Ige OM, Oladokun RE. Treatment outcome of newly diagnosed sputum positive adult tuberculosis cases in the context of HIV infection. Journal of Infectious Diseases and Immunity 2011; 3(10): 210-217. http://www. academicjournals.org/JIDI 
25. Daniel GD, Mohammed AY, Luelseged TC, Lopisso EK, Bernt L. The rate of TB-HIV co-infection depends on the prevalence of HIV infection in a community. BMC Public Health 2008,8:266 PubMed doi:10.1186/14712458-8-226. http://www.biomedcentral.com/1471$2458 / 8 / 226$.

26. Salako AA, Daniel OJ. A Four-Year Retrospective study of HIV in Tuberculosis Patients at the Ogun State University Teaching Hospital, Sagamu. Journal of Community Medicine and Primary Health Care 2001;13:24-35.

27. Purushottam AG, Jayant DD, Deepak BP. Prevalence of Pulmonary Tuberculosis among HIV positive patients attending Antiretroviral Therapy Clinic. N Am J Med Sci 2013; 5(6): 367 PubMed -370. Doi: 10.4103/194-2714. 114169.

28. Sebsibe T, Takele T. HIV co-infection among tuberculosis patients in Dabat, North-West, Ethiopia. Journal of Infectious Disease and Immunity 2013; 5(3): 29-32. Doi 10.5897/JIDI 2013.0117. http://www.academicjournals. org/JIDI.
29. Falodun OI, Cadmus EO, Alibi P et al. Delayed treatment seeking behaviours and associated factors among pulmonary tuberculosis patients in Ibadan, Nigeria. African Journal of Epidemiology 2014; 2(1): 27-33.

30. Muvunyi CM, Masaisa F, Bayingana A et al. Prevalence and diagnostic aspects of sputum smear positive tuberculosis cases at a tertiary care institution in Rwanda. Afr J Microbiol Res 2010; 4: 88-91.

31. Sophia V, Prahlad K, Lakbir SC et al. Treatment Outcome and Mortality at One and Half Year Follow Up of HIV Infected TB Patients Under TB Control programme in a District of South India. PLos One 2011; 6(7): 1 PubMed -8. Doi: 10.1371/journal.pone.0021008

32. Pontororin GJ, Kenangalem E, Lolong DB et al. The burden and treatment of HIV in tuberculosis patients in Papua Province, Indonesia: a prospective observational study. BMC Infect Dis 2010; 10:362 Doi: 10.1186/14712334-10-362. 